\title{
Algumas observações sôbre adubações de Citrus
}

\author{
PHILIPPE WESTIN CABRAL DE VASCONCELLOS
}

Relataremos aqui alguns fatos observados em plantas já em produção.

Em artigo que há tempos publicamos, fizemos referência à asserção muito frequente entre os lavradores que têm plantado em seus pomares mudas cítricas enxertadas: "de que após produzirem, com regularidade, abundantes colheitas, começam a entrar em decrepitude aos dôze anos".

Ao assumirmos a chefia técnica da Secção de Horticultura, pudemos constatar êsse fato. De doịs pomares cítricos existentes, um, o mais velho, estava pràticamente perdido e restava sòmente a solução de substituí-lo. $O$ outro denunciava já os evidentes sinais de decrepitude, justamente quando ia passando dos dôze anos...

Constatando o ataque de moléstia e pragas, procedemos, neste, à pulverização dos troncos, ramos e copas com caldas mistas e fizemos a calação dos troncos e pernadas. Aguardado o resultado, năo se apresentou animador; as plantas continuavam com aspecto triste, como que mortiço. Só nos restava, pois além daquele tratamento, derivar para a adjuvação do solo, com adubações. 
Plantado que fôra, em terra roxa das melhores, em derrubada de antigo e rico capoeirão, pôde dispensar por muitos anos adubação. Chegada,porém, áquela idade que os práticos davam como crítica, era evidente o aspecto depauperado das plantas.

Passámos, então, a fazer também,anualmente, a adubação química, ainda que moderada. A reação foi notabilíssima; as árvores retomaram o aspecto sadio, voltaram a produzir bastante, conforme fomos controlando nos anos sucessivos. Tiveram bỏa produção, indo à idade de 32 anos nesse ritmo e a muito mais iriam, se năo sobreviesse a tristeza, a malfadada podridão das radicelas, que as afetou, por estarem, como os setenta e cinco por cento dos Citrus do mundo, enxertadas sôbre a laranjeira azêda (C. aurantium, L.).

Para não sermos muito fastidiasos com algarismos em excesso, vamos dar um balanço nas produções, exigências e fornecimentos de elementos nutritivos, às três árvores mais velhas que deram origem à "Bahianinha de Piracicaba", dentre as quarenta e oito, de diversas castas que compunham o lote $\mathbf{A}$.

Veja-se o gráfico da produção das 3 matrizes de Bahianinha de Piracicaba em 10 anos, não obstante o fornecimento anual de milhares de borbulhas para enxertia.

Consideremos que as quantidades de elementos nutritivos retirados por cento das colheitas de laranjas de umbigo, segundo os dados analíticos publicados pelo Boletim n. 93 da Estação Experimental da Universidade da California (citação de Hume), orçam por :

$\begin{array}{ll}\text { Azoto (expresso em N) } & 0,211 \% \\ \text { Fósforo (expresso em P20 5) } & 0,051 \% \\ \text { Potássio (expresso em K20) } & \mathbf{0 , 2 1 5 \%}\end{array}$

Pois bem, com exceção do fósforo, nós demos durante dez anos, uma insignificante adubação mineral, comparada com as exigências das plantas e tão sòmente no que diz respeito à frutificaçấo, conforme se depreende dos seguintes quadros e gráficos : 


\section{BAHIANINHA DE PIRACICABA}

Quantidade de frutos colhidas em 10 anos nas três árvoresmães, ainda que mutiladas

\begin{tabular}{l|r|r|r|r|r|r|r|r|r|r}
\hline Epocas & 1927 & 1928 & 1929 & 1930 & 1931 & 1932 & 1933 & 1934 & 1935 & 1936 \\
Idades (anos) & 16 & 17 & 18 & 19 & 20 & 21 & 22 & 23 & 24 & 25 \\
Bahianinha n. 1 & 360 & 588 & 500 & 220 & 300 & 280 & 586 & 387 & 210 & 300 \\
Bahianinha n. 2 & 720 & 1165 & 400 & 350 & 400 & 260 & 571 & 385 & 215 & 380 \\
Bahianinha n. 3 & 700 & 740 & 500 & 804 & 200 & 490 & 1344 & 528 & 270 & 400 \\
\hline
\end{tabular}

BAHIANINHA DE PIRACICABA

Pêso em quilogramas dos frutos colhidos em 10 anos nas três árvores-mães

\begin{tabular}{l|r|r|r|r|r|r|r|r|r|r}
\hline \#pocas & 1927 & 1928 & 1929 & 1930 & 1931 & 1932 & 1933 & 1934 & 1935 & 1936 \\
Idades (anas) & 16 & 17 & 18 & 19 & 20 & 21 & 22 & 23 & 24 & 25 \\
Bahianinha n. 1 & 80 & 120 & 92,5 & 46,2 & 64,5 & 64,4 & 119 & 79,5 & 39,9 & 78 \\
\hline Bahlaninha n. 2 & 100 & 240 & 88 & 70 & 84 & 57,2 & 118 & 79 & 38,7 & 91,2 \\
\hline Bahianinha n. 3 & 120 & 160 & 155 & 144,7 & 42 & 102,9 & 273 & 121,5 & 51,3 & 92 \\
\hline
\end{tabular}




\section{BAIANINHA DE PIRACICABA}

OUANTIDADE DE FRUTOS COLHIDOS EM 10 ANOS

NAS TRÊS ARVORES-MÄES, AINDA OUE MUTILADAS.

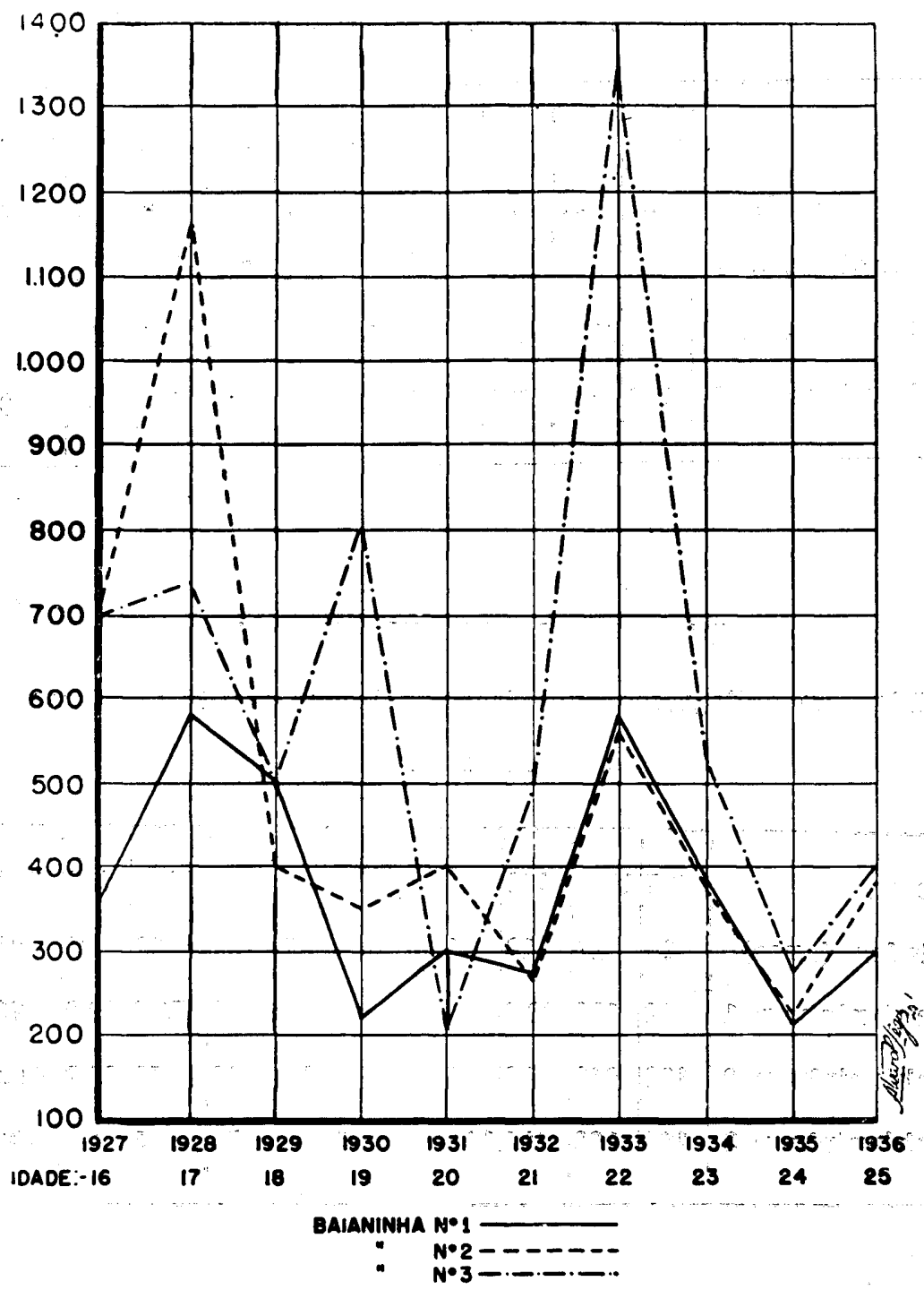




\section{BAIANINHA DE PIRACICABA}

PESOS, EM KILOGRAMOS DOS FRUTOS COLHIDOS

EM 10 ANOS, NAS TRÊS ARVORES-MAEES.

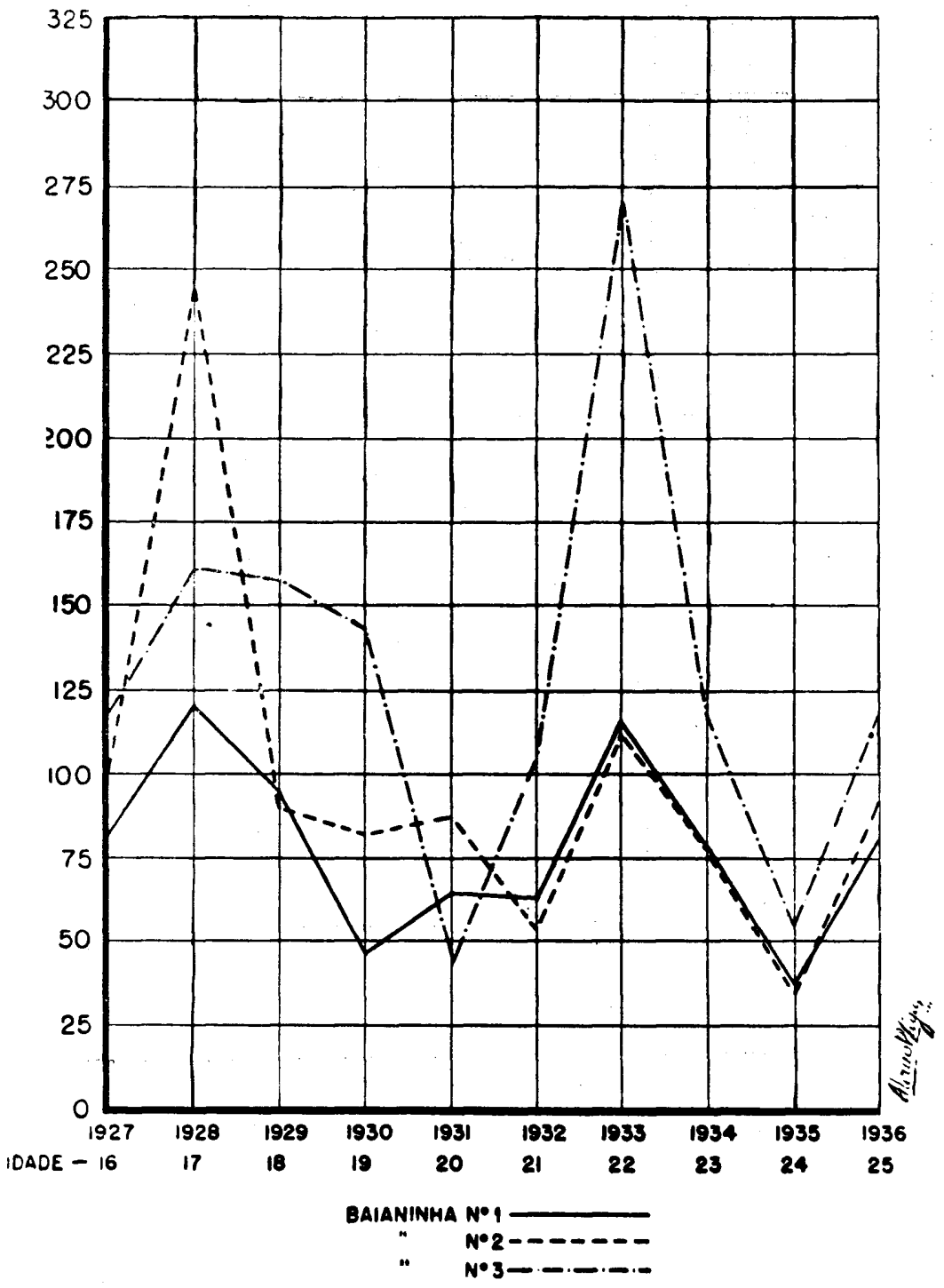




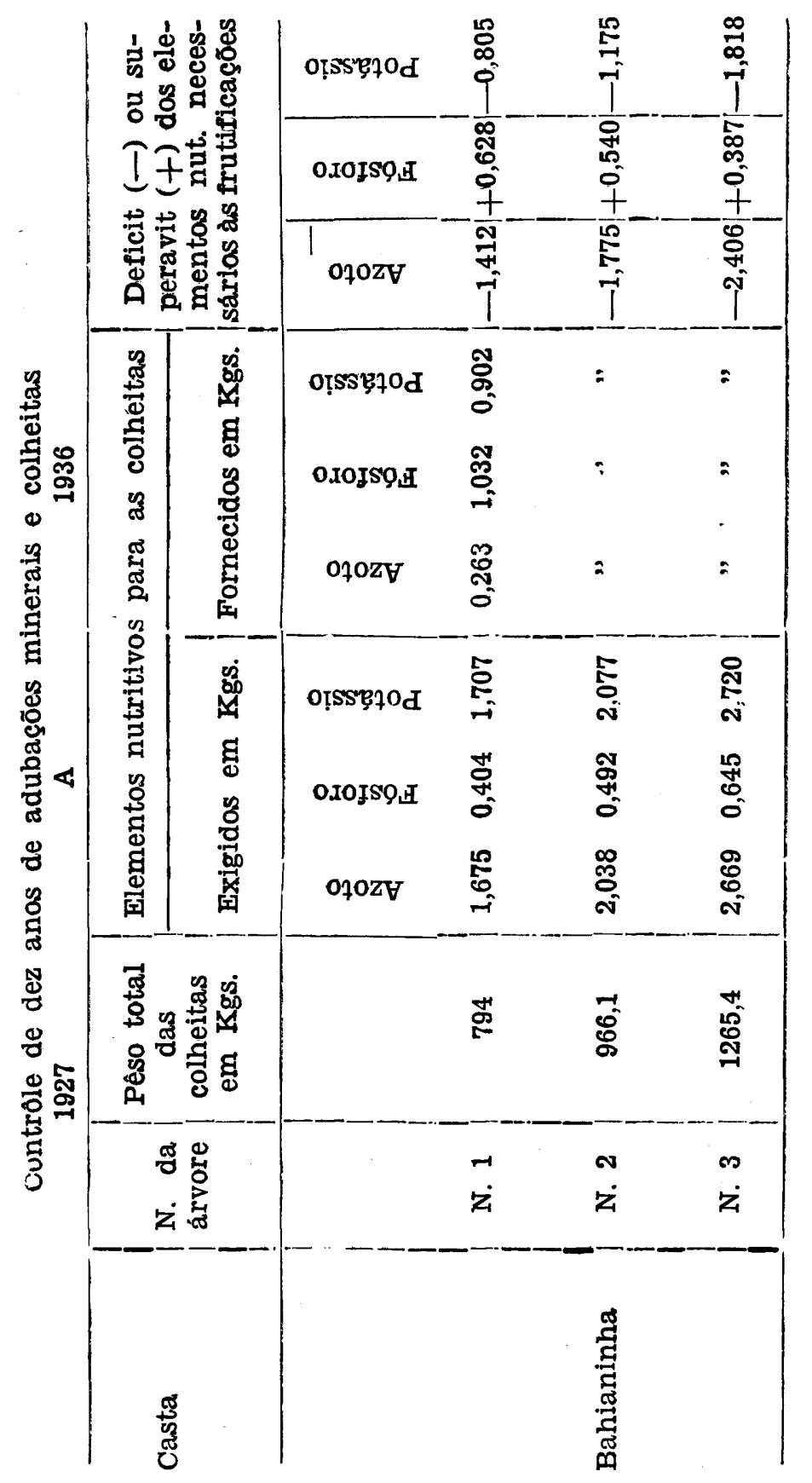


As adubaçóes foram iniciadas em 1926, motivo por que as colheitas desse ano năo foram computadas.

No lote A em que estavam essas plantas, o azoto fol ministrado na forma de sulfato de amóneo, o fósforo na de superfosfato simples e o potássio na de sulfato. Do quadro referido deduz-se que, com exceção do fósforo que fol dado em maior quantidade do que a exigida táo somente pelas produçరes de frutas, os outras dois (azoto e potássio) se apresentam em deficit.

Entretanto, tendo sido restabelecido o vigor das árvores de modo satisfatório, quis isso dizer que os receberam por outras formas. Além do azoto das deficientes adubaçбes quimicas, o dos poucas adubos verdes somados ao contido nas águas pluviais, satisfizeram as necessidades das plantas. Houve mesmo anos em que as cascas dos frutos apresentaram-se pouco mais espessas, indicio esse de certo excesso de alimentaçáo azotada. Tal fato alfim nos levou a interromper, temporariamente, a adubaçáo verde com leguminasas e fornecer a matéria orgânica com a celfa das más ervas, constituidas pela predominancla de Gramineas, tendo de permelo Compostas, Cyperáceas e Oxalideas, etc.

As adubações verdes com cultura de leguminasas foram feitas respectivamente em:

\begin{tabular}{|c|c|c|c|c|}
\hline Ano & Adubos verdes & Epoca de semeadura & $\mid \begin{array}{c}\text { Epoca } \\
\text { de corte }\end{array}$ & $\begin{array}{l}\text { Matéria ver- } \\
\text { de da parte } \\
\text { aerea dada a } \\
\text { cada arvore }\end{array}$ \\
\hline 1929 & $\begin{array}{l}\text { Feljáo de Porco } \\
\text { (Canavalia en- } \\
\text { siformes, D C) }\end{array}$ & $\left\{\begin{array}{c}19-12 \\
(1 \times 0,50 \text { em triangulo } \\
2 \text { linhas }\end{array}\right.$ & $\mid 16-4-930$ & $11,9 \mathrm{Kgs}$. \\
\hline 1930 & $\begin{array}{l}\text { Hervilha azul } \\
\text { (Clitoria ter- } \\
\text { natea, L.) }\end{array}$ & $6-12-930$ & \multicolumn{2}{|c|}{$\begin{array}{l}\text { Diversos pequenos } \\
\text { cortes até } 1936\end{array}$} \\
\hline
\end{tabular}


Tem sido, de fato, êsse o elemento nutritivo chave, muito especialmente no concernente ás qualidades para exportação. Em demasia, dá frutos bagaçasos e pode estragar completamente a resistência inerente à pequena espessura e firmeza que devem apresentar o pericarpo e o mesocarpo (albedo) das laranjas a serem transportadas para longe. Para o futuro, isso talvez não venha a ter tanta importancia, visto já estarem aperfeiçoadas as métodos de extração e preparo de suco de laranja enlatado, com grande economia de frigorificaçăo, pêso e volume, nos transportes e dilação do prazo de consumo. Consta mesmo das planos de nosso Governo Federal, a instalação de usinas para se dar início entre nós a semelhantes empreendimentos.

E' também acoimado o excesso de azoto de afetar a fecundidade das árvores cítricas, fazendo produzir internódios longos com muita abundância de grandes fólhas verde-escuras luzidias, enfraquecendo as plantas com relação ás intempéries e pragas.

Mas a escassês dêle também prejưdica, tendo como consequência uma vegetação precária, com fôlhas amarelecidas.

O fato de ter havido maior gasto pelas plantas, do que o concernente á adição de adubos minerais, deficientes em nitrogênio e por espaço de dez anos, levando em conta tžo sòmente o consumo para sua frutificaçăo, veio demonstrar que nảo era êsse o elemento nutritivo que estava atuando como minimo.

Quanto ao fósforo, dissemos acima, fol fornecido a mais do que as necessidades das colheitas feitas. Devemas, porém, observar que não trouxe prejuizo pelo exctesso dado, sôbre o retirado por elas, pois teve que satisfazer também as outras necessidadies da planta, tais como: reforma das ramificaçбes e da folhagem, crescimento das raizes, etc.

Teremos que acrescentar que tais plantas sofreram, em anos sucessivos, grandes amputações de ramos com borbulhas destinadas à enxertia em nossos veveiros e nos de outrem. Nao fôra êsse fato, as suas produçóes de frutas seriam ainda malores. Além disso, temos verificado que, nos nassas solos e para certas castas de plantas cítricas, o fósforo, a mais, quer na forma de superfosfato, quer na do pó de assos, tem sido benéfico, melhorando a qualidade e a classificação comercial. Os tecnicos em citricultura lhe reconhecem o efeito no aumento da colheita, desenvolvimento normal dos frutos e mesmo, adiantamento da maturação. Há ainda a consignar aqui, a geral pobreza de nassas solos nesse elemento nutritivo. 
Com referéncia ao potássio, vimas pelo quadro que a quantidade fornecida pela adubação apresentou deficit. Tratando-se, porem, de uma terra roxa, com grande profundidade, a planta podie retirá-10, com o seu vasto sistema radicular, explorando grande cubo de terra, compensando a parte que faltou na adubaçăo para a frutificaça e mals aquela gasta na restauraçăa e crescimento de seus orgăas dando ainda resistência aos mesmos.

A formaçáo sob a qual demas o potássio, fol a de sulfato a (48\% de $\mathrm{K} 20$ ); assa tem sido a mais preconizada para plantas citricas, dentre as que se ncontram normalmente no comércio. As análises dos sucas das frutas não mastraram a esperada deficiencia dele que se refletiria em balxo teor de solidas solúveis, com relaçá a acidez. Assim, após quatro anos de adubaçбes, revelaram, dentro da primeira quinzena de maio o seguinte :

\begin{tabular}{c|c|c|c}
\hline Castas & $\begin{array}{c}\text { N. da } \\
\text { arvore }\end{array}$ & $\begin{array}{c}\text { Acidez expressa } \\
\text { em ácido citrico, } \\
\text { \% em péso do suco }\end{array}$ & $\begin{array}{c}\text { Relaçá acidez } \\
\text { solidas solúveis } \\
\text { do suco }\end{array}$ \\
\hline Bahianinha & N. 1 & 0,873 & $1: 12,54$ \\
N & N. 2 & 0,770 & $\begin{array}{c}1: 12,72 \\
1: 11,77\end{array}$ \\
\hline Médias & N. 3 & 0,832 & $1: 12,501$ \\
\hline
\end{tabular}

Para Citrus, o carbonato de potássio do comércio tem-se revelado também bom adubo, como acontece d̀s cinzas de lenha. Estas, especialmente, aplicadas em outros pomares sob as nossos culdados, tem feito produzir frutos de muita apresentaçăo, sapides e aroma, com grande preferencia por parte dos consumidores.

No que se refere ao cloreto de potássto, Hume faz neserva, dizendo "que a qualidade da colneita às vezes se prejudica". Nós, causualmente, tivemos uma dura prova com o emprêgo de mistura em que entrava o potássio em forma de cloreto: - encarregado da aplicaçáo de adubas enganou-se e trocou dita fórmula que se destinava a jardim, empregando-a no pomar 
a dêste para aquele. As plantas floriferas nada revelaram de desagradável, mas as citricas do pomar, passaram a produzir frutos intragáveis. Algumas quinze pessoas, dentre as quais três agrónomos e um farmacéutico, que anteriormente costumavam consumir elogiando os ótimas citrus, reclamaram, sem exceção, contra o mau sabor que passaram a apresentar. Uns diziam que estavam com um gósto relaxado, outros que eram salobros e assim por diante.

Fol geral para as variedades e espécies all cultivadas, o maleficio : Laranjas Bahia, Lima, Tangerina, Cravo, todas delxaram de ser procuradas, ainda que gratis...

0 peior fol que, com essa única aplicação em terreno xistoso, o péssimo sabor persistiu por alguns três anas, para só delxar de ser perceptível no quinto, após tal adubação equivocada.

Além do cloreto de potássio, em tal mistura entraram outras adubas, fazendo estes, normalmente, parte das fórmulas que comumente temas empregado, sem jamais terem dado semelhante resultado: nåo houve senăo atribuir ao cloreto, tão maléfico efeito.

Voltando a comentar as resultados obtidas com a reação da planta, empregando as fórmulas citadas no começo deste artigo, as provas indiciárias nos levam a conclusta de que 0 elemento nutritivo que estava funcionando como mínimo teria sido o fósforo, pois as outras dois dados em deficiencia náo impediram uma regular vegetação das plantas depois de terem passado por um evidente periodo de caréncia. 